\title{
Practical Psychodynamic Formulation
}

\author{
John Farnsworth and Gerald Maclaurin
}

\author{
Psychotherapist, Dunedin; Psychotherapist, AUCKLAND
}

\begin{abstract}
We outline a practical approach to psychodynamic formulation to show how useful it can be within the demands of ordinary clinical practice. To do so, we break down the components of a dynamic formulation using a variety of examples. We draw on the Triangle of Insight (Jacobs, 2006) and the Triangle of Persons (Malan, 1979) as our main model of formulation and compare it to other approaches. By doing so, we aim to illustrate how formulation is a flexible, effective tool for therapeutic assessment. The article also outlines a way of thinking through written case formulation, discussed primarily through an extended case example.
\end{abstract}

\section{Waitara}

Ka huaina e māua he tirohanga aropā ki te tauirahanga hinengaro kia mōhiotia ai tōna painga i roto i ngā nonoi o te mahi haumanu. Kia taea ai ka whāia ètahi tauira hei arohaenga i ngā waehanga tātainga hikareia. Ka huri ki te Mātauranga ā-Tapatoru (Jacobs, 2006) me te Tapatorunga ā-Tangata (Malan, 1979) hei whainga tauira matua tātai ka whakataurite ki ètahi atu tirohanga. Mā tēnei, e whai ana māua kia tauirahia te ngāwari, te whai hua o tēnei hāpai hei arohaenga haumanu. E huaina anō hoki he momo whakaarohanga mai i te tauira tuhinga whakaarahanga matua i tētahi whakaroanga tauira tuhinga.

Keywords: psychodynamic; formulation; hypothesis; Triangle of Insight; Triangle of Persons; object relations

It is not uncommon for psychotherapists to find themselves grappling with how to do a case formulation. Yet, formulating is an invaluable guide to what lies ahead with a client and what to keep an eye on. But how to do this? What model of formulation to choose? How effective will it be and is it worth the time investment anyway? What follows is a practical approach to psychodynamic formulation. Being practical, it does not cover every variation, nor review every available model, of which there are plenty. What it does set out, however, is a way of drafting out a formulation within the demands of ordinary clinical practice. It is designed to provide a flexible, effective tool that enables a therapist to appraise the

Farnsworth, J; Maclaurin, G. (2015). Practical psychodynamic formulation. Ata: Journal of Psychotherapy Aotearoa New Zealand, 19(2),145-158. DOI:10.9791/ajpanz.2015.14 (c) New Zealand Association of Psychotherapists Inc. 
complexities that clients bring into a typical New Zealand therapy space. It is also designed to provide a guide to written case formulation so that a therapist can have confidence in capturing key aspects of the client relationship they are assessing. We outline what a psychodynamic formulation is, and is not, and look at some comparative approaches to formulation. Throughout, we draw on clinical examples and vignettes and introduce fragments of formulations. We also work through a specific case so that each step in a formulation becomes clear as it is developed. As part of this, we provide a commentary so that the reader can reflect on the material and thinking that is presented as it unfolds.

\section{What is a Formulation?}

The first distinction to make is simple: a formulation is not a diagnosis. It does not rely on any version of the DSM (American Psychiatric Association) or ICD (World Health Organization) manuals, nor on the Psychodynamic Diagnostic Manual (PDM) (Psychodynamic Task Force, 2006). It can, of course, be used very effectively in conjunction with any of these, but it is not a diagnosis. The difference, broadly speaking, is that if a diagnosis is a single snapshot of a client's current functioning, a formulation is closer to an ongoing, living document. The difference is implicit in the double meaning suggested by the concept of dynamic formulation. On the one hand, dynamic forces are by nature unstable and changeable; on the other, a formulation attempts to crystallise out what appears to be constant within this flux. Like any living document, then, a dynamic formulation is mutable, open to revision and may well change as the work and the relationship in the room demand. It is a hypothesis about what lies ahead. As such, it may not be especially long: at most, a page or perhaps two. "Dynamics", of course, also refers to what takes place within the client and between the client and therapist: the shifting, volatile, fluid, emotionally impregnated, often unconsciously motivated interactions intrinsic to relational work. So, a psychodynamic formulation focuses on how internal and external dynamics are patterned, their implications, and how they may be expected to unfold.

Mr D was born prematurely to a teenage mother who had a postpartum depression. He had severe separation anxiety as a child and spent long periods of time home "sick". It is possible that his mother's depression affected Mr D's ability to develop a secure attachment and that this made it hard for him to think of himself as a separate person. This may have impeded his capacity to separate successfully from his mother. Now, it may be making it difficult for him to be apart from his wife for more than one night. (Cabaniss et al, 2011, p. 6)

\section{What are Dynamics?}

Faced with a client in the room, how do we reduce the constantly unfolding interactions we encounter to some useful lines on a page? How not to be continuously immersed in the grief, anxiety, anger, depression, unconscious manipulation, cold hate, trauma or detached indifference that may occupy the chair opposite? What of these fluctuating interactions are 
significant, what passing? What of the stream of feelings and impressions are mine and what his or hers?

As therapists know, these shifting, compelling engagements provide just the information needed to develop a formulation. What we are looking for, within these ebbs and surges, are patterns: repeating patterns of affect, expression, and behaviour. Defining such patterns produces evidence that can be used in a formulation.

One way of detecting significant patterns is to draw on what is known as the Triangle of Insight (Jacobs, 2006). The triangle has been employed in a wide variety of formulation models (Butler \& Binder, 1987; Drury \& Alim, 2014; Lapworth \& Sills, 2010). Commonly, it includes three elements: "out there", "back then", and "in here". The original triangle published by David Malan (1979), from work developed in the Menninger Clinic (1988), referred to the Triangle of Persons: others, parent, therapist. The two triangles are very similar but the latter emphasises the transferential aspects of client relationships. Combining the two triangles, the parallels are quite clear. "Out there" is similar to others - relationships that a client is commonly engaged with; "Back Then" is usually early experience: parents, in Malan's description, or significant family and whanau; "In Here" is with the therapist and ongoing interactions in the room.

$P$ is a sensitive and introverted person in whom the early death of his father and the problematic relationship with an absent or uninvolved mother played an important role in the development of his depression. His depressed mother could not respond to his needs and was experienced as a "bad object" leading to feelings of aggression towards her and insecure attachment.

Being, however, dependent on his mother, aggressive feelings were repressed and internalized and he developed a false, compliant self. An internal process of splitting led thus to the identification with a bad internal object and dependency on external "good objects". The splitting was reinforced by the death of his father, which caused a regression and reawakening of oedipal conflicts, a conflict from which he, with the death of his father, emerged as the victor. His main defense mechanisms at present are rationalization, intellectualization, repression and passivity. (Bohmer, 2011, p. 276)

The value of the triangles are that they allow a therapist to identify and track patterns of relationship. All the fluid affect, expression, and behaviour, moment by moment, can be charted against these three points. More than that, the triangles enable the transferential quality of interactions, usually unconscious, to be borne in mind. They also allow a therapist to plot each point of the triangle against another: for example, "Back Then" experiences will usually come "In Here" when they are unresolved and will play out in the room somehow. Likewise, "Back Then" experience is most likely to shape interactions with friends, colleagues, and current partners.

Hinshelwood (1991, p.166) translated these three elements into object relations language: 
Three areas of object-relations (the current life situation, the early infantile relations and the transference relationship) are focused upon to derive a common pattern. From these core object-relationships a point of maximum pain can be hypothesised and the attendant defensive relationships.

His three areas equate to the three points of the triangle. But Hinshelwood (1991) went much further than just deriving a common pattern, important as this is. What he illuminated is how the pattern itself is an attempt to deal with acute, albeit hidden, distress and how this is managed by building up "attendant defensive relationships" (p.166). The pain, we assume, is what brings clients to the room. Paradoxically, they attempt to avoid it through defensive strategies they employ either with us, with friends or with others. A psychodynamic formulation allows the therapist, using the Triangle of Insight, to identify patterns that link the fluctuating feelings, behaviours, and accounts encountered in their room.

Alternative formulation models include other elements. Cabiniss et al (2013, p. 4), commented that there are:

Cognitive behavioral therapy (CBT) formulations, psychopharmacologic formulations, and family systems formulations - just to name a few. Each type of formulation is based on a different idea about what causes the kinds of problems that bring people to mental health treatment.

Consequently, they also highlight different aspects of what to identify. For instance, Faden and McFaden (2015) argued for an acronym called PRESS, so that a therapist can "use PRESS to craft a concise psychodynamic formulation”. PRESS stands for Psychologically minded, Relationships, Ego Strength, Stimulus and Superego. For some psychotherapists, an acronym may be a more useful memory tool; for others, it includes more issues to contend with in creating a formulation. This approach, like every other, has its own history (Kassaw \& Gabbard, 2002; Perry, Cooper, \& Michels, 1987). Likewise, Cabaniss et al (2011) proposed a formulation based on "Describe, Review and Link" which breaks down stages in developing a formulation into three steps to highlight the unconscious elements a client presents.

Cabaniss et al (2011) presented their model in book length form and so did Nancy McWilliams (1999) whose approach to psychodynamic formulation is widely known and used. Chapter by chapter, she discussed assessments of unchangeable aspects of the self, developmental issues, defences, affects, identifications, relational patterns, self-esteem, and pathogenic beliefs. Such a comprehensive approach is beyond the scope of this article, but is well worth consulting. It is enough to note here, however, that like the triangles of insight and persons, it is rooted in a psychodynamic model grounded in the unconscious.

Why, then, choose the Triangle of Insight as a basis for psychodynamic formulation? Primarily, because it has accumulated an enduring history that attests to its robustness and utility. In short, it demonstrates a consistent and useful way of making sense of what clients bring to the room. It also offers a relatively simple, flexible formula that is clinically applicable. Of course, it can be supplemented by other forms of assessment, whether these include psychological mindedness and ego strengths (for example, see Faden \& McFadden, 2015), personality patterns or mental functioning offered by the PDM (Psychodynamic Task 
Force, 2006), or by specific diagnostic criteria in the DSM manuals (American Psychiatric Association).

\section{Developing a Psychodynamic Formulation}

The Royal Australian and New Zealand College of Psychiatrists (RANZCP) provided a crisp summary of what a formulation contains: "Why does this patient suffer from this (these) problem(s) at this point in time?” (RANZCP, n.d.; Reilly \& Newton, 2013). This is good as far as it goes, but it has a medical emphasis that we want to modify. Our modification adds all the dynamics around a presentation, particularly the overt and implicit interactions with the therapist that their formulation overlooks.

One other aspect before we continue. When should we formulate? Certainly, it's helpful, if not essential, for long-term psychodynamic work. Yet, formulation was originally developed in short-term work (Malan, 1979) where it is equally effective. Short-term, in this context, often means around 20 sessions. With very brief work: three, six or 10 sessions, which is often the case with Employee Assistance Programmes and other treatments, circumstances do not allow much room for a formulation. That said, even a mental sketch, or a summary, of key elements can be helpful as a guideline under the pressures of brief intervention work. At its very least, it is a valuable discipline whose value increases the more it is used.

Formulating often needs several sessions in order to see or confirm repeated patterns. Coltart (1988), on the other hand, demonstrated that a single interview can establish an effective formulation. However, this involves a mastery that takes time and enough cases to develop. Here, we recommend time over speed to gain security in formulating.

In what follows, we break down an existing formulation and comment on its sequence of steps and thinking. For practicality, we use the Triangle of Insight ("Out There", "Back Then", "In Here") as our guideline. We also emphasise that the formulation is a working hypothesis and that, commonly enough, it will fit into a page. This requires summarising and concision, which are always good skills to have at hand.

Illustration: Ms F: "I have difficulty maintaining relationships with others". She confesses she is drawn to people who are cruel or abusive. [CLIENT HISTORY]

She describes traumatic childhood experiences with a mother who displayed wildly inconsistent, frightening behaviour. [CLIENT PRESENTATION]

She speaks softly; she is awkward and hard to hear, and her therapist is surprised how irritated she begins to feel. [EVOKED RESPONSE/TRANSFERENCE]

The therapy relationship is likely to be disrupted and work towards developing a secure sense of self is likely to be slow and hard-won. [WORKING HYPOTHESIS] 


\section{The Elements of a Formulation}

The illustration above outlines how a presentation might be broken down into constituent elements. Piece by piece, each statement distinguishes different aspects that constitute the elements needed for a formulation. First, Ms F briefly elaborates her difficulty with relationships (client history). This leads to curiosity about how this has come about - in this case, through early trauma (client presentation). Then the therapist's own experience in the room is described (evoked response/transference). Lastly, this suggests a possible hypothesis about how the therapy may unfold.

Even this very simple example provides a considerable amount of information. From the start, the reader can get a sense of being drawn along, with new questions coming to mind after each statement. Why, for example, does she have difficulty maintaining relationships? Why is she drawn to cruel, abusive people? So, how does she come across in herself? Why, then, is her presumably compassionate therapist irritated? What to make of her therapist's surprise about this? All these build a picture with the questions leading to a hypothesis that attempts to draw the elements together. Incidentally, because it is a hypothesis, another therapist might frame it differently. This one focuses on the likely dynamics in the room suggested by the history. But an alternative, for example, might highlight more about the client's core conflict of being attracted to cruel relationships. These differences in perspective may reflect a therapist's own orientation or theoretical background. A therapist mindful of Johnson's (1994) character styles may see the presentation through this lens and emphasise, say, the implications of the hated or abandoned child.

Similarly, as more detail is disclosed, the overall presenting picture may change. New information about unrevealed significant figures, resilience factors, trauma or other complicating material mean the formulation may need adjusting: for this reason, it is a working hypothesis. Nonetheless, it still provides a useful thread - one that can always be returned to when the vicissitudes of the therapy relationship are in full flower.

Lastly, it is worth noting that the formulation implicitly draws on the Triangle of Insight: "Out There" is the difficulty maintaining relationship with others; "Back Then" encompasses her traumatic childhood experiences, whilst "In Here" includes the client's soft voice and the therapist's conflicted response. The triangle helps to frame up the significance of what is presented and gives it a focus. As Hinshelwood (1991) suggested, it identifies the area of maximum pain that has created the distress bringing this client to therapy.

\section{Jill: Dynamic Formulation}

With this in mind, we unpack a more complex formulation that draws on a fuller case history. Yet, many of the same elements outlined above can still be identified. In what follows, we lay out the presentation of a clinical case, comment briefly as the formulation develops, and enter into more detailed discussion. As this account emerges, however, it is worth the reader asking what gaps, blind spots or shortcomings it may have. In this sense, we hope to allow the reader to be a detective following the detective work of the original formulation. 


\section{Initial Presentation}

Jill approached me as someone who she knew did "counselling". She appeared as a lean, intense, European woman in her mid-4os with a wiry physique and angular features. She wore no make-up and had dark, greying, slightly unruly, shoulderlength hair. She wore loosely fitting, inexpensive clothes and there was an air of mild neglect about her appearance.

We get a vivid picture of this woman as she first appears to the therapist. Paying attention to these details and the therapist's observations often provide valuable clues for a later formulation.

She told me she was determined to make changes to herself and her life even though she often felt hopeless and absolutely inadequate to this task. She related her intense frustration with her husband George's apathetic approach to work (in his housepainting business and in the home), his drinking, and his attempts to control her. ("Your problem is that you think too much. You should listen to me more and do what I tell you.") In coming to therapy she believed she was making a life and death choice for herself and was increasingly aware of the impact this choice would have on her children, who she was determined would have a better upbringing than the one she had experienced.

By now, the client and her life have come to life in quite a dramatic way. There are also clues about what has prompted her decision to seek therapy. Her central relationship, with George, along with her mixture of hopelessness and determination are all clearly spelt out. There are also hints of a history - her upbringing - which lies in the background.

Jill was the third child in her family, with two older brothers and one younger sister. The family was poor and lived in poor housing for much of her childhood. Her parents argued acrimoniously and often. Her mother she remembers as clinging to her for support against her father even while she was fiercely critical of Jill. Her father she remembers as more consistently warm and interested in her. However as she became adolescent his warmth included a sexual interest in her and she began to fear their conversations, which he would frequently load with sexual innuendo towards her. In addition he had strong, complex views on the nature of reality, God, and philosophy which frequently confused and frightened her. Their ambiguous discussions finally culminated in him asking her to have sex with him when she was 18 years old. She refused and increasingly distanced herself from him but was unable to confront him or tell anyone else what had happened.

We now have this history with its turbulence, complexity, and key conflicts. In a different context, this could be rich material for a novel.

Throughout Jill's childhood, her parents were frequently both absent from the home - her father often away looking for labouring work while her mother was 
teaching. Jill was thus often left alone in charge of her younger sister, feeling lonely, inadequate, and also intimidated by her brothers. She found school difficult and struggled with learning, even appearing "backward" to her teachers. She again felt intimidated, unable to adequately express herself to most of her teachers and rarely felt understood.

This further information considerably extends the picture we already have, adding a wealth of new detail that depicts how difficult and miserable Jill's early years were. There is more to follow.

In her early 20 Jill was raped on two separate occasions. She felt devastated by these abuses, confused, ashamed, and out of control. She did not report either rape and often thought of killing herself. It was around this time that she met and married her husband who came to live at the family home as a border.

In the context of what we already know, this new disclosure comes as a shock. Hard on its heels comes the news of how she came to be married. For any therapist, there is a lot to absorb, both in terms of information and emotional impact. The material also presents dilemmas, particularly for emerging therapists: what to focus on; what is central; what should be peripheral, since it all seems important; how not to let one's own sympathies colour what we have just encountered?

It is out of just this confusion that a formulation has to be created: how to weigh one aspect against another, particularly with the live presence of the client close by. How, then, does this particular therapist, confronted by this material, proceed?

At this point, in fact, it can be useful to think how any reader would tackle a formulation knowing, now, what they do. Some readers may regard the rapes as most salient; others, her desperate family life. Some may concentrate on her current relationship with George and how it came about. In each case, it is likely that the choice of attention will be shaped by the conceptual or theoretical lens a reader brings to bear. For instance, a psychodramatist, faced with this material, might highlight the links between her original social and cultural atom (her family of origin) and her current social atom (her significant current relationships) and might consider how these shape her central cluster of roles - progressive, coping or fragmented as they unfold in the therapy room. Whatever the approach, this is how the dynamic formulation might actually be developed.

\section{Dynamic formulation/hypothesis}

Jill presented for therapy with a relatively normal-appearing outer life, apparently functioning in the roles of homemaker, mother, wife, and part-time cleaner. Internally, however, she reported feeling desperate, lonely, and absolutely inadequate to the tasks of daily living.

In this case, the formulator begins with a brief summary before plunging into deeper analysis. The analysis begins by outlining the impact of her background. In particular, it picks out key dynamics in her early life. 
From her history it seems plausible that her mother's intensely critical attitude and neediness towards her, combined with an openly bitter conflict between her parents led to early blocks in her ego development. Given the family's poverty, living in substandard housing with both parents frequently absent it seems likely that the family milieu could often have been chaotic and unsafe for a young child. Her environment must have increasingly appeared dangerous and unpredictable to her and Jill's response was to withdraw from this unpleasant world.

The description highlights the unresolved tensions in Jill's family and her primary response to "this unpleasant world". In other words, the formulation begins to identify her family context as central to Jill's experience of life as a whole. Then it moves to address exactly how the formulator assessed this context's effect on Jill's inner world. The assessment picks out her withdrawal as the linchpin for this analysis, spelt out in a fairly dense way.

Within this withdrawal, I believe, lay a failure to master what Erikson named as the essential task of the toddler - the capacity for autonomy. Instead Jill would be burdened with the shame, self-doubt, and sense of inadequacy which have continued to plague her throughout her life. Initially at least she would cling, like a drowning sailor, to the damp uncertain life raft of her father's ambiguous interest in her, even as this gradually disintegrated with his absences, frightening theories, and sexual intrusions. My thinking here is that these early dependency traits (as indicated by her extreme dependency on, and identification with, George early in their marriage and a similar process with me in therapy) was complicated by several opposite trends as she grew older. Thus both parents were often absent, she was given excessive early responsibility for her small sister, and her attacking mother leaned heavily on Jill for support.

A considerable amount of thinking takes place in this passage, thinking based on a series of implicit conceptual frames. These include mostly unnamed ideas about what constitutes the essential task of the toddler; what dependency and dependency traits involve, and the concepts of identification and transference and how they are manifested with Jill. In setting the details out in this way, these lenses start to bring a shape to Jill's story and experience. Together with her own life circumstances, they form the platform on which a more theoretical formulation is constructed.

Nevertheless, using Benjamin's (1996) analysis of the dynamics of dependent personalities I assess the following: combined with her withdrawal and the impossible "parenting" demands placed upon Jill, her father's controlling, patronising responses critically strengthened her passivity and sense of inadequacy and helped foster this perspective with other people. I believe this early relationship with her father led to the features of dependency so apparent later in her life, rather than a simple avoidance pattern, even though she did appear to others first as unremarkable, almost hidden, and then later as intellectually backward and socially inept. Whatever the balance between dependency or avoidance, her talents for singing, drawing, and 
dance became tragically truncated and a gulf opened up between her and the rest of the world.

There are many points of interest in this passage. For instance, this formulation develops a controlling focus on her father's role. Her mother's presence is implicit; it is the powerful link between her father and her own dependency and passivity that takes central place. Alongside runs an implicit commentary about the choice of theoretical lenses: "a simple avoidance pattern" rejects the idea of attachment theory (avoidant attachment) in favour of a more classically Freudian or object relations perspective focused on parental dynamics, boundary impingements, and self-mastery. This picture subordinates the experience of neglect, the rapes, Jill's difficult schooling and the family's poverty. Inevitably, a formulation highlights some aspects over others; our interest here is how the choices are made, not whether they are right or wrong. The formulation continues:

Jill came to believe she could neither connect with others, nor escape their judgement of her obvious "deficiencies", and committed herself to emotional isolation. In her relationships with most others she maintained a marked submissiveness, all the while attacking her own "pathetic weakness", and felt equally judged by the world.

This paragraph largely expands what has gone before whilst emphasising, again, her poor self-esteem and passivity. It leads to its conclusion:

Reading Janet Frame's Faces in the Water, I am vividly reminded of Jill's isolation. "A great gap opened in the ice floe between myself and the other people whom I watched, with their world drifting away through a violet coloured sea where hammerhead sharks in tropical ease swam side by side with the seals and the polar bears. I was alone on the ice. A blizzard came and I grew numb and wanted to lie down and sleep." (Janet Frame, 1961, p. 10)

The reader can speculate on the impact of this passage through simply reading it. Recourse to literature is unusual in a formulation but its appearance here suggests an attempt to capture the essence of Jill's inner world in a way she cannot do herself. At the same time, it evokes a powerful empathic image for the formulator where the bizarre juxtaposition of tropics and ice captures something of the juxtaposed powerlessness and destructiveness sensed by the formulator.

\section{The Formulation Discussed}

Is this a model formulation? We do not believe so and, when we invited a workshop of 40 therapists to analyse it, they did not think so either. That said, models of anything can often seem so unreachably perfect they have limited use in actual practice. Instead, this is an illustration of how one therapist attempted to come to grips with a complex client: we believe its main value lies in how the therapist went about it.

For instance, we have already pointed to the choices made by the therapist. A different set 
of choices, highlighting the influence of Jill's mother over her father, would arrive at quite a different formulation. Moreover, if her maternal influence was couched in the language of attachment theory (that Jill suffered from an avoidant ambivalent attachment) the formulation would be reshaped again. If both parents were more highlighted, it is reasonable to believe the therapist would eventually experience both sets of transferences in the room as Jill alternated between maternal and paternal identifications (Messler Davies, 2015).

Of course, this raises the question of the formulator's gender - would this affect the formulation, let alone the course of treatment? We cannot know. However, we can speculate whether some of the male transferential issues might have come more alive with a male than a female therapist: for instance, those around Jill's father and her husband, George, let alone the rapes she suffered.

In turn, this raises the question of trauma and trauma literature where Jill's double violation is concerned. A formulation which accounts for Jill's trauma will alert the therapist to possible contradictory responses in the work ahead that cannot otherwise be explained. Without it, a therapist is more prone to missing cues and repeating devastating transferential experiences.

The question of theory also arises. The theoretical lens of Benjamin's (1996) dependent personalities makes itself felt in how the formulator thinks. There are two issues here but they both highlight what the formulation, and then the therapy, will pay attention to. One issue is psychodynamic: Benjamin's work highlighted the "crucial dimension" to be parental control and sets up the idea of dependence (1996, p. 227-228). Yet, the concept of control influences the formulation itself by emphasising the central influence of Jill's father. By contrast, for instance, more recent approaches have constructed the self as dialogic and not just controlled (Salvatore et al 2012; Preda \& Piccione, 2012). This has implications not just for how we see the shaping of Jill's self taking place, but also how we interpret our interactions in the room. So, for the reader, a dilemma emerges: is this formulation shaped by its quite specific theoretical orientation or does the material lend itself best to an account of Jill in terms of a dependent personality reading? From our perspective, what is important is to keep in mind that any formulation necessarily goes hand in hand with a conceptual framework, just as Jill's case illustrates.

The second issue is diagnostic. Dependent personality is very close to Dependent Personality Disorder as described in the DSM-IV (American Psychiatric Association, 2000). On the one hand it can be very useful to have an overlap between a diagnosis and a formulation. On the other, diagnosis and formulation, as we emphasised initially, are very different procedures. It is tempting, but possibly hazardous, to conflate the two too quickly. In this case, we suggest the emphasis in a formulation is best kept on the dynamics of the work.

Dynamics returns us to the Triangle of Insight. If we apply it to this formulation, we can frame it in terms of the three points of the triangle. "Out There" includes Jill's husband and her children (though their presence is only hinted at); "Back Then" is clearly her complex family circumstances - the role of her parents and her formative experiences; but "In Here" is the least spelt out. We know how Jill presents herself, but we know very little about her impact on her therapist or their joint transferential dynamics. We can, of course, speculate. We might hypothesise, for instance, that a solid working alliance will take a long 
time to form and will be strongly shaped by Jill's ambivalent attachment; that she may see the therapist as alternatively controlling and paternal, or critical and needy, depending on whichever transferential matrix or self-state is in play.

Whatever the case, the Triangle of Insight highlights key areas for consideration in constructing a workable formulation and for identifying central dynamics and defences. This, as we have noted, is regardless of modality or theoretical orientation. Of itself, it may not provide the nuances in a formulation. These might include issues of resilience or ego strength raised in the PRESS model, or the relative emphasis to give to trauma, cultural or social environments, or any other variable. But it does suggest three central areas to keep in mind that consistently foreground relational dynamics. In a nutshell, we might say it provides a practical, reliable means to make the unconscious conscious.

With all these ideas in mind, it is possible to think about how, or whether, to rewrite this formulation. Could it be more condensed and still convey the same information? Could it strengthen its emphasis on the role of Jill's mother; could more be said about the therapist's response to Jill's presentation; is there a place for the role of trauma? All these might shape a rewritten formulation. If we take Hinshelwood's (1991) injunction seriously, the formulation will attempt to identify the area of "maximum pain" and how this is defended against. More recent literature may emphasis the shifting states of the self as carrying multiple areas of pain, each of which needs addressing individually (Bromberg, 2009, 2014).

\section{Conclusion}

We began by outlining the flux of emotions that every therapist experiences with clients: how to make sense of these and pick out what is important from such a continuous flow of sensations, observations, and thoughts. We suggested that identifying the patterns that emerge from this experience is a key strategy. What patterns we attend to will, in turn, be influenced by the theoretical lens we bring to bear: different lenses inevitably highlight different patterns. Yet, these patterns provide the groundwork for a dynamic formulation, in particular, a groundwork which is alert to the unconscious communications in the room. The fragments we included are illustrations.

We proposed that a formulation based on the Triangle of Insight is a highly reliable method to use for typical clinical work. This is because it brings together aspects of the client's past, their present circumstances, and the felt experience with the therapist in the room. It has the capacity to reveal unconscious motivations and provide a guide, a hypothesis, to what may unfold in the sessions ahead. In unpacking a detailed hypothetical formulation we also suggested that no formulation is perfect - but, then, it is a hypothesis so, of course, it is open to correction and revision as we discover more.

Above all, however, we want to emphasise that a dynamic formulation is practical: it is something we can use with increasing ease and speed in any area of short- or long-term work. Whether we write it out formally as a page or more, or just jot down notes, we have found it a good habit of mind, one that enables us to reflect on, engage with, and attend to the relationship before us. 


\section{References}

American Psychiatric Association. Diagnostic and Statistical Manual of Mental Disorders. Washington, DC: Author.

American Psychiatric Association. (2000). Diagnostic and statistical manual of mental disorders (4th ed). Washington, DC: Author.

Benjamin, L. S. (1996). Interpersonal diagnosis and treatment of personality disorders (2nd ed.). New York, NY: Guilford.

Bromberg, P. M. (2014). Standing in the spaces: Essays on clinical process trauma and dissociation. New York, NY: Routledge.

Bromberg, P. M. (2009). Multiple self-states, the relational mind, and dissociation: A psychoanalytic perspective, In P. F. Dell \& J. A. O’Neil (Eds.) Dissociation and the dissociative disorders: DSM-V and beyond (pp. 637-652). New York, NY: Routledge.

Butler, S. and Binder, J. L. (1987). Cyclical psychodynamics and the Triangle of Insight: An integration. Psychiatry, 50: 218-231. doi: 10.1521/00332747.1987.11024354

Cabaniss, D. L., Cherry, S., Douglas, C. J., \& Schwartz, A. R. (2011). Psychodynamic psychotherapy: A clinical manual. London, UK: John Wiley \& Sons.

Drury, H. \& Alim, N. (2014). Integrative psychotherapy in intellectual disabilities: Using cognitive-behavioural and psychodynamic formulations. Advances in mental health and intellectual disabilities $8(3), 197-209$.

Faden, J. \& McFadden, R. (2015). Use PRESS to craft a concise psychodynamic formulation. Current Psychiatry, 14(5), 12-13.

Freda, M. and Picione, R. (2012). Relational and organizational value of self-positions (Commentary). International Journal for Dialogical Science, 1, 51-60.

Hinshelwood, R.D. (1991). Psychodynamic formulation in assessment for psychotherapy. British Journal of Psychotherapy, 8, 166-174. doi: 10.1111/j.1752-0118.1991.tbo1173.x

Jacobs, M. (2006). The presenting past; The core of psychodynamic counselling and therapy (3rd ed.). Maidenhead, UK: OU Press.

Johnson, S. (1994). Character styles. New York, NY: W.W. Norton \& Company.

Kassaw, K. \& Gabbard, G. (2002). Creating a psychodynamic formulation from a clinical evaluation. American Journal of Psychiatry 159(5), 721-726. doi: 10.1176/appi.ajp.159.5.721

Lapworth, P., \& Sills, C. (2010). Integration in counselling and psychotherapy: Developing a personal approach. London, UK: Sage Publications.

Malan, D. (1979). Individual psychotherapy and the science of psychodynamics. London, UK: Butterworth.

McWilliams, N. (1999). Psychoanalytic case formulation. New York, NY: The Guilford Press.

Messler Davies, J. (2015). From Oedipus complex to Oedipal complexity: Reconfiguring (pardon the expression) the negative Oedipus complex and the disowned erotics of disowned sexualities. Psychoanalytic Dialogues: The International Journal of Relational Perspectives, 25(3), 265-283. doi: 10.1080/10481885.2015.1034547

Perry, S., Cooper, A. \& Michels, R. (1987). The psychodynamic formulation: Its purpose, structure, and clinical application. American Journal of Psychiatry, 144(5), 543-550. doi: 10.1176/ ajp.144.5.543

Psychodynamic Task Force. (2006). Psychodynamic Diagnostic Manual. Silver Spring, MD: Alliance of Psychoanalytic Organizations. 
Reilly, J., \& Newton, R. (2011). Formulation: A proposal for a more structured, longitudinal approach. Australasian Psychiatry, 19, 4: 301-305. doi: 10.3109/10398562.2011.601312

RNZACP. (n.d.) RANZCP clinical examinations formulation guidelines for trainees. Retrieved from https://psychiatry-training.wiki.otago.ac.nz/images/6/6c/RANZCP-Formulations-Guide.pdf

Salvatore, G., Carcione, A. \& DiMaggio, G. (2012). Dependent self in narcissistic personality disorder in comparison to dependent personality disorder: A dialogical analysis.

International Journal for Dialogical Science 6(1), 31-49.

World Health Organization. The ICD-10 classification of mental and behavioural disorders:

Clinical descriptions and diagnostic guidelines. Geneva, Switzerland: World Health Organization.
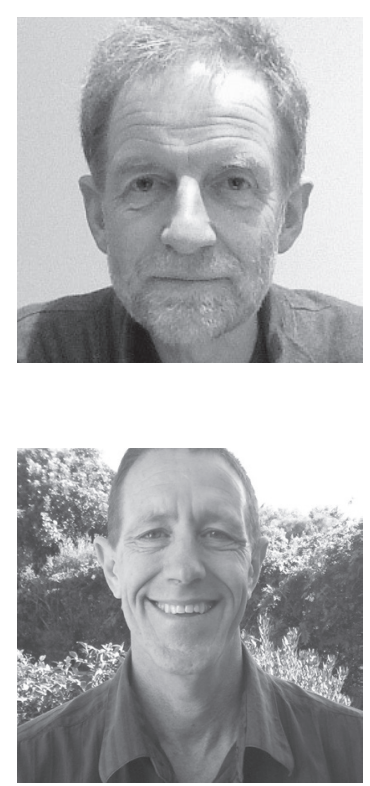

John Farnsworth is a psychotherapist in private practice at 555 George Street in Dunedin. He works with individuals, couples, and groups in both short and long-term work. Whilst he draws on object relations and interrelational approaches, these are part of a wide variety of perspectives. He has an extensive training in psychodrama and has published in sociology and social science fields. Currently, he is a moderator for the written ACP and is a member of the NZAP Council. Contact details: johnf@earthlight.co.nz .

Gerald Maclaurin has a private practice in psychotherapy and supervision in Auckland, and is a moderator for the NZAP ACP Written Assessment. He has a keen interest in the process of supervision for psychotherapists and other health professionals. Contact details: gerald.m@xtra.co.nz . 